\title{
Increasing postpartum contraception in rural Uttar Pradesh: Implications for behavior change communication
}

Population Council

Follow this and additional works at: https://knowledgecommons.popcouncil.org/departments_sbsr-rh

Part of the Demography, Population, and Ecology Commons, Family, Life Course, and Society

Commons, Health Policy Commons, International Public Health Commons, Maternal and Child Health

Commons, Obstetrics and Gynecology Commons, Public Health Education and Promotion Commons, and the Women's Health Commons

How does access to this work benefit you? Let us know!

\section{Recommended Citation}

Population Council. 2010. "Increasing postpartum contraception in rural Uttar Pradesh: Implications for behavior change communication," Shaping Demand and Practices to Improve Family Health Outcomes in Northern India Policy Brief no. 7. New Delhi: Population Council. 


\section{Increasing postpartum contraception in rural Uttar Pradesh: Implications for behavior change communication}

\section{Background}

Evidence shows that closely-spaced pregnancies pose health risks to mothers and newborns. Adequate spacing-24 months from delivery to the next pregnancy could save the lives of mothers and newborns ${ }^{1}$. However, national-levael surveys show that adoption of contraceptive methods for spacing has remained low in India, including rural Uttar Pradesh (UP), despite the fact that many women (50 percent) desire at least a threeyear gap between two births. NFHS-3 data (2005-06) show that among married women aged 15-34 in rural UP, only 20 percent were using any contraceptive method for spacing ${ }^{2}$.

In October 2009, the Population Council conducted a formative study in rural UP. The objectives of this study were to assess the level of adoption of postpartum contraception for spacing among low parity women, identify the facilitating factors and barriers to the adoption of this target behavior, and identify programmatic and behavior change communications (BCC) initiatives that could accelerate the adoption of postpartum contraception for spacing and improve the service delivery system, if required, to facilitate the process. The project was funded by the Bill and Melinda Gates Foundation.

\section{Methodology}

The formative study was conducted in two phases. First, a survey was conducted covering 4,754 households, 4,472 currently married women aged 15-34 years who delivered a child in the last three years, 2,274 husbands, 2,372 mothers-in-law, 289 ASHAs, 284 AWWs, 161 ANMs, 316 local private practitioners, 251 panchayat members (including Village Health and Sanitation Committee members) and staff at 144 government health facilities (PHCs/CHCs) from 225 villages in 12 districts spread over the Western, Central and Eastern regions of UP. In the second phase, 308 in-depth interviews were conducted with family-level stakeholders (women, husbands, mothers-inlaw), health care providers (ASHAs, AWWs, private practitioners, dais) and panchayat members to complement the information gathered in the quantitative survey. The qualitative study was conducted in 24 villages: eight villages each from three districts, one district from each of the three regions.

\section{Key findings}

Status: Amongst currently non-pregnant women aged 15-34 years who gave birth in last three years $(\mathrm{N}=4,049), 41$ percent were using a contraceptive method in the postpartum period. Of these, 27 percent were using modern methods while 14 percent were depending on traditional methods. Condoms (14 percent) and the safe days method (11 percent) were most commonly used methods.

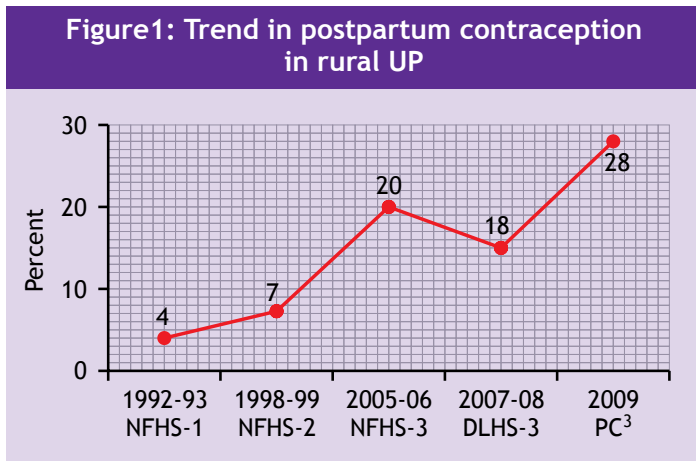

Note: Among currently married women aged 15-34 who had given birth in the 12 months preceding the survey.

\footnotetext{
${ }^{1}$ R. Smith et.al. 2009. Family Planning Saves Lives. Washington, DC: Population Reference Bureau.

${ }^{2}$ Data from NFHS-1, NFHS-2, NFHS-3 and DLHS-3 presented in this policy brief are based on an analysis conducted by the Population Council of currently married women aged 15-34 in rural UP who had given birth in one year preceding the survey. ${ }^{3}$ S. Goel, I. Bhatnagar, M.E. Khan and A. Hazra. 2010. "Increasing Postpartum Contraception in Rural Uttar Pradesh: Implications for Behavior Change Communication," in M.E. Khan, Gary Darmstadt, T. Usha Kiran and D. Ganju, eds. Shaping Demand and Practices
} to Improve Family Health Outcomes: A Formative Study in Rural Uttar Pradesh. New Delhi: Population Council (forthcoming). 


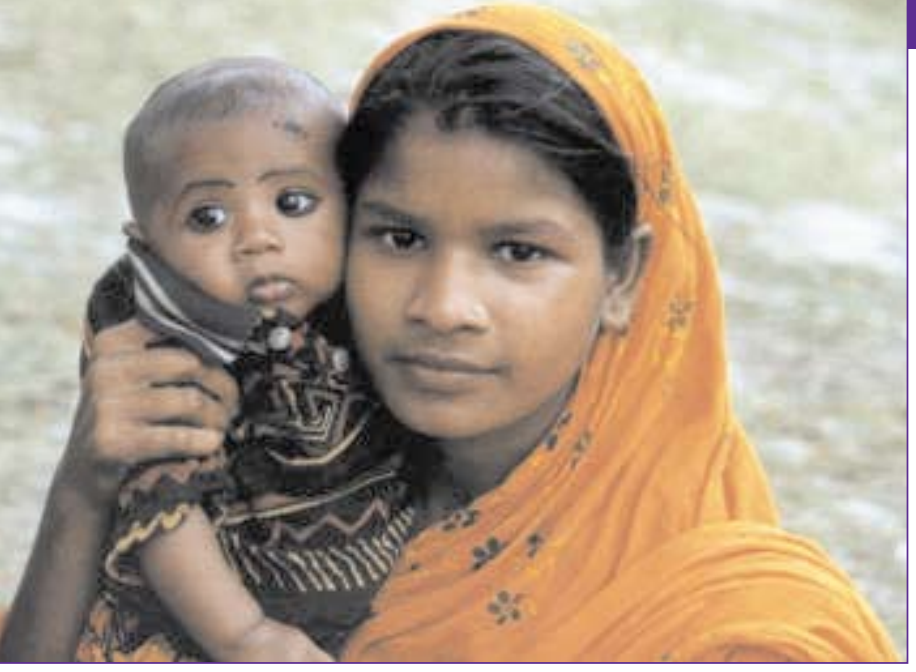

Figure 1 shows the trend in postpartum contraceptive use in rural UP among women who had given birth in the 12 months preceding the survey, indicating that postpartum contraception is slowly increasing.

Regional variations in the use of modern contraceptive methods are evident. Rates were higher in the Western and Eastern regions of UP (each around 31 percent) as compared to the Central region (22 percent) (ANOVA test, $\mathrm{p}<0.001$ ).

Amongst 4,049 women, 54 percent said they were not using any contraceptive method and perceived themselves to be protected from unwanted pregnancy as their child was small (35 percent) or their menstruation has not resumed (29 percent) (Figure 2).

Figure 2: Reasons for not using any contraceptive method in the postpartum period (percent)

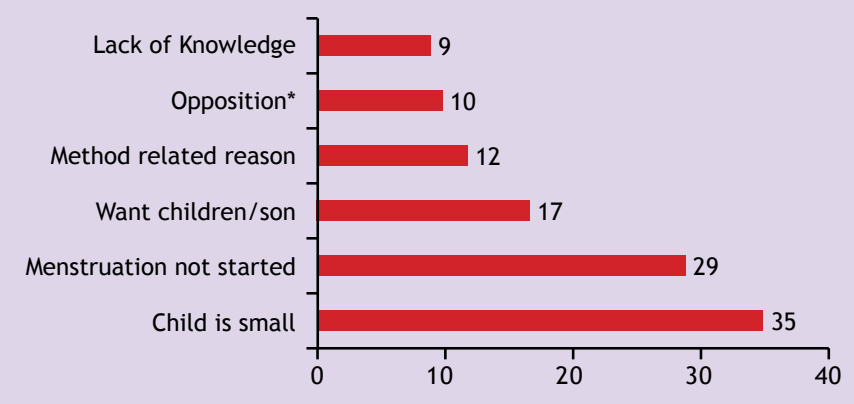

Note: Among women who reported non-use of a contraceptive method $(\mathrm{N}=2,194)$.

* Includes self, husband, family and religion. Percentages may not add to 100 due to multiple responses.

Taking the three criteria of $\mathrm{LAM}^{4}$, further analysis shows that among women with a child less than 6 months $(\mathrm{N}=880), 76$ percent were at risk of unwanted pregnancy. Among women with a child aged 6 months or more $(\mathrm{N}=3,169), 53$ percent were at risk of unwanted pregnancy. Thus, among the total 4,049 women, 58 percent were at risk of unwanted pregnancy.

Among currently pregnant women ( $\mathrm{N}=423), 62$ percent reported the pregnancy was unwanted while for 38 percent it was a desired pregnancy, primarily to have a son. As one woman informant said: "I want more children as all are girls.

${ }^{4}$ Lactational Amenorrhea Method (LAM) is a natural contraceptive method that protects women from unwanted pregnancy for up to 6 months after delivery, only if the following three criteria are met: a) the child is less than 6months of age; b) the child is being exclusively breastfed; c) the woman's menstrual cycle has not resumed.
Therefore I am not using anything right now. One boy should be there to take care of the household." An analysis of the reasons for unwanted pregnancy ( $\mathrm{N}=265$ women) revealed that 23 percent had delayed adopting contraception, 11 percent got pregnant before resumption of their menstrual cycle, 7 percent reported method failure while for 13 percent fear of side effects discouraged them from adopting a method. For the remaining 43 percent, women's lack of authority and family-level opposition (from self, husband) to adopt a method resulted in the unwanted pregnancy.

Amongst all women ( $\mathrm{N}=4,472), 87$ percent were aware of at least one contraceptive method for spacing. Awareness was high for oral contraceptive pills (OCPs; 80 percent) followed by condoms (67 percent) and IUD (46 percent). In contrast, awareness of injectable contraceptives was only 12.8 percent, and emergency contraceptive pills for use in case of unprotected sex was just 0.6 percent.

\section{Barriers}

Low awareness on the critical consequences of closely spaced births: The most commonly reported adverse consequence of closely spaced births, as perceived by ASHAs, husbands and women, were the mother becomes weak (ranging between 80-89 percent) followed by the baby being low birth weight (43-48 percent of ASHAs and husbands, 22 percent of women). Other critical or fatal complications like miscarriage, pregnancy complications, stillbirth or child death during delivery were mentioned by very few (Table 1). ASHAs' lack of knowledge would need to be addressed as they are key change agents at the community level.

\begin{tabular}{|c|c|c|c|}
\hline & Women & Husbands & ASHAs \\
\hline Woman becomes weak & 80 & 87 & 89 \\
\hline Low birth weight/smaller baby & 22 & 48 & 43 \\
\hline Miscarriage & 14 & 13 & 20 \\
\hline Stillbirth & 10 & 15 & 15 \\
\hline Pregnancy complications & 17 & 23 & 25 \\
\hline Child may die during delivery & 5 & 10 & 20 \\
\hline Total & 3,699 & 2,274 & 281 \\
\hline
\end{tabular}

Note: Percentages may not add to 100 due to multiple responses.

No knowledge of LAM and timing of the return of fertility: Four-fifths (80 percent) of all women $(\mathrm{N}=4,472)$ did not know how soon a woman can become pregnant after delivery. In-depth interviews reveal that most believed that women can become pregnant only after their menstrual cycle resumes. Knowledge of LAM and its use was almost negligible ( $<1$ percent) among all the stakeholders in the family. A typical response during the qualitative study was: "I do not know about LAM. If the menstruation cycle does not come then how can anyone get pregnant?"

Frontline health workers' knowledge of LAM was also poor: Only 6-7 percent of ASHAs and AWWs, and 22 percent of ANMs had correct knowledge of LAM. 
Misconceptions and fear of side effects of OCPs and IUDs: Among non-users of contraception, 17 percent of women had not adopted a method as they wanted the next child soon. Of the remaining 1,814 women, 11 percent were not practicing contraception due to fear of side effects. The most commonly reported side effects of OCPs were that it makes the woman feel hot, cause rashes, harms the uterus and results in infertility if used continuously. For example, a woman said: "In the village people say that the use of pills $[O C P S]$ will cause illness. I had taken Mala-D after my first child was born but my stomach used to bloat." For IUDs, commonly reported side effects were heavy bleeding, harm to the uterus, and movement of the IUD to the heart which causes death. According to a woman: "My menstruation has just started so my husband told me to get an IUD. I told him that I'm scared because my neighbor got it and she had heavy bleeding."

Incorrect knowledge of rhythm/safe days method: Though the safe days method is the second most commonly used method (11 percent) after condoms, in-depth interviews reveal incorrect knowledge and practice. Many women and husbands believe that the first 10 days of the menstrual cycle is the most unsafe period. A husband said: "We don't have sex for 16 days from the day the menstrual cycle starts, as women get pregnant during this time; my friends told me this."

Lack of counseling efforts by frontline health workers: Most women (80 percent) did not receive any advice on spacing or family planning methods either during ANC or at the time of discharge. PNC contact, which also provides an opportunity for family planning counseling, was limited; just 14 percent of women reported PNC contact with any frontline health worker.

Frontline health workers' reluctance to involve husbands in family planning counseling: Although 39 percent of ASHAs and 20 percent of ANMs mentioned that the husband is the key decision-maker on reproductive and contraceptive issues, only 12 percent of ASHAs reported that they had advised husbands on birth spacing or contraceptive methods. An ASHA said: "I do not talk to men on this topic as they are our elders. They avoid talking to me on such issues and I also feel shy talking to them."

Programmatic emphasis on limiting births: As sterilization continues to be the focus of the family planning program, few young low parity women are approached and advised to use contraceptives for spacing. Only 21 percent of women were given any advice on contraception to space births at the time of discharge from the facility after delivery $(\mathrm{N}=1,979)$.

Moreover, ASHAs get a performance-linked fee for promoting sterilization, and hence promoting spacing methods is not considered to be profitable. Woman also had similar views about frontline health workers: "nasbandhi waali behenji [the lady who promotes sterilization, probably the ASHA/ANM] just tells to get the operation [sterilization] done."
Facilitating factors

Background characteristics: Women's background characteristics such as educational attainment (education up to Class 10 or above; OR 1.29, p<0.05) and high standard of living (OR 1.63, $\mathrm{p}<0.001)$ facilitate the adoption of the desired practice.

Spousal communication: Logistic regression analysis shows that women who discussed family planning with their husband were four times more likely to adopt postpartum contraception (OR 4.57, $\mathrm{p}<0.001$ ) than others. Hence, a BCC campaign to trigger spousal communication on family planning could lead to the uptake of the practice.

IPC through frontline health workers: The study shows that for 50 percent of women, the ASHA/ANM is the preferred source of information on birth spacing and contraceptives. Logistic regression shows that women who received advice twice about family planning were more likely to adopt postpartum contraception (OR $1.63 \mathrm{p}<0.001$ ) than those who were not advised at all.

Exposure to birth spacing messages: Exposure to birth spacing messages and information increases the likelihood of use of family planning methods. The analysis shows that among women who had heard or seen any message on birth spacing in the last three months, 50 percent were using a contraceptive method while among those who had no exposure to birth spacing messages, only 37 percent were using a method ( $\mathrm{z}$ test, $\mathrm{p}<0.001$ ).

\section{Implications for the BCC strategy}

Source of information on family planning for women and men differ: For media planning due consideration should be given to the fact that though the preferred source of information is frontline health workers (50 percent), women mainly received birth spacing messages from friends and neighbors (39 percent) and their spouse (26 percent), while husbands mainly received birth spacing messages from the mass media (65 percent from the radio and 59 percent from TV) and posters/ banners displayed at health centers and other public places.

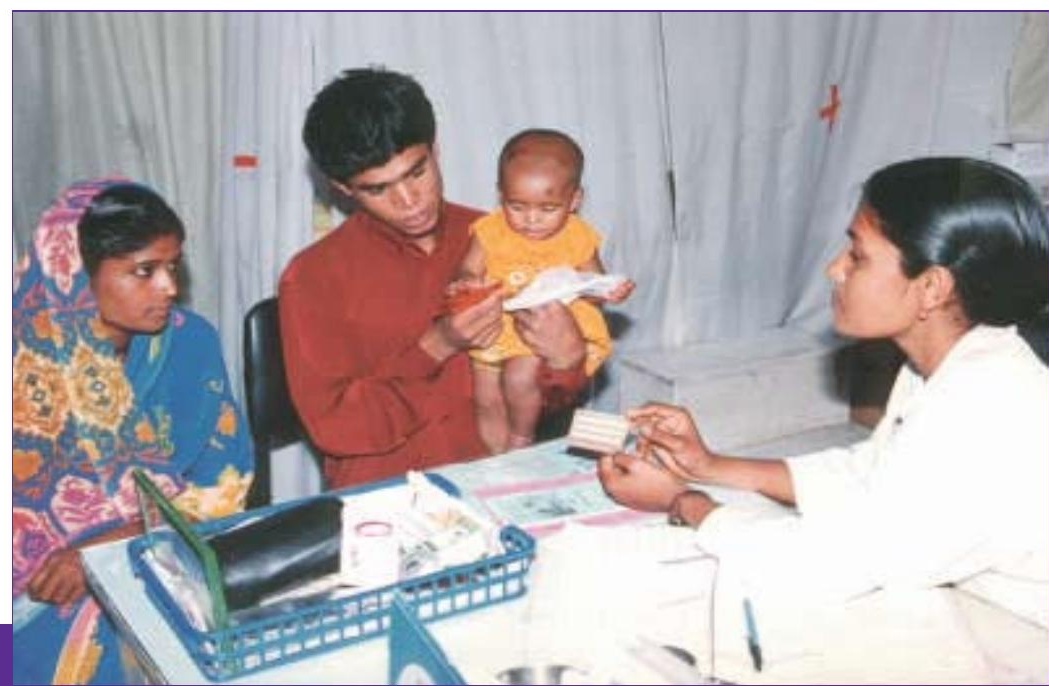


Husband's involvement is important: Husbands are key influencers and decisionmakers for the adoption of postpartum contraception. BCC efforts focused on the husband to promote spousal communication for decision making on the adoption of contraception for spacing could help to promote mother and child health and to reduce the burden on the family economy. In the context that almost two-thirds of men (those who are educated up to Class 9 or above) in UP can be reached by a combination of the press, TV and radio ${ }^{9}$, BCC efforts to reach men through the mass and mid-media, such as community radio, may be effective and could help in triggering spousal communication.

Janani Suraksha Yojana (JSY) provides counseling opportunities: The increase in three ANCs and institutional delivery due to JSY presents additional opportunities for provider contact with couples. These opportunities should be optimally utilized to ensure that birth spacing advice is given during ANC and pre-discharge counseling. Currently 47-70 percent of frontline health workers have received any counseling aids. Use of counseling aids by frontline health workers could increase the effectiveness of counseling.

Addressing myths and misconceptions: ASHAs' counseling aids should include information to dispel myths and misconceptions among couples regarding contraceptives. A choice of mass media and mid- media could be used to reinforce this information.

Orientation on LAM: A re-orientation of all frontline health workers is necessary to promote the correct practice of LAM and timely transition to modern contraceptive methods. A home visit by the ASHA in the fifth month post- delivery is crucial to facilitate this transition from LAM to modern contraceptive methods and to provide advice on initiating complementary feeding.

Message alignment: Messages on birth spacing should be aligned with those on newborn health, exclusive breastfeeding and timely introduction of appropriate complementary feeding to comprehensively address mother and child health.

Reaching the unreached: The limited mobility of women, especially young daughters-in-law, prevents them from accessing information on birth spacing. An effective method to reach such groups would be to provide information through IPC in small groups, for example, during self-help group meetings and Village Health and Nutrition Days. The ASHA is a depot holder for promoting spacing methods like condoms, OCPs and emergency contraceptive pills; ASHAs could be given a small fee to supply these products, which could lead to deeper rural penetration of contraceptives.

${ }^{5}$ Indian Readership Survey, 2009.

Suggested citation: Population Council. 2010. Increasing postpartum contraception in rural Uttar Pradesh: Implications for behavior change communication, Policy Brief No. 7. New Delhi: Population Council.

For additional information, contact: Population Council, Zone 5A, India Habitat Centre, Lodi Road, New Delhi 110003, or email info-india@popcouncil.org

\section{(2) Population Council}

Research that makes a difference
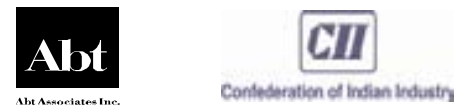

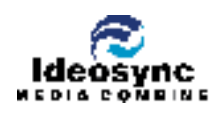

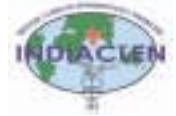

s $\mathbf{s}$

W
A
M

The opinions expressed in this publication do not necessarily reflect the views of the funding agencies. 